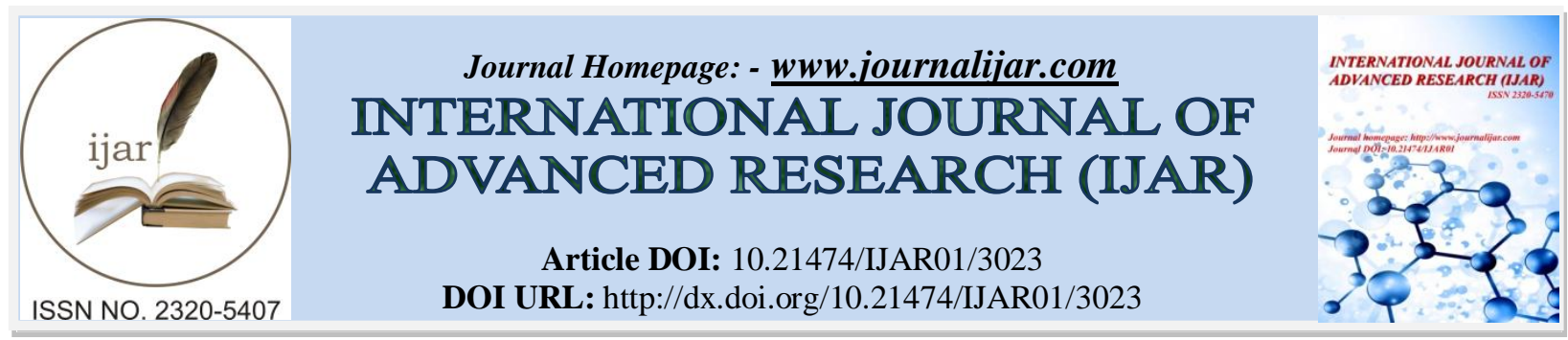

RESEARCH ARTICLE

\title{
INTEGRATING IMAGING TECHNIQUES IN DEEP INFERIOR EPIGASTRIC PERFORATOR BREAST RECONSTRUCTION.
}

\author{
Asif Bahhati ${ }^{1}$, Andreas Gravvanis ${ }^{2}$, Dimitrios Karakitsos ${ }^{3}$, Bader Saeed ${ }^{4}$, Waleed Mardini ${ }^{4}$, Anas Alhasoun ${ }^{4}$, \\ Abdulmalik Alghamdi ${ }^{4}$, Salman Mardini ${ }^{4}$ and saleh alshammari ${ }^{5}$. \\ 1. Plastic and Burn Department, King Saud Medical City, Riyadh, KSA. \\ 2. Microsurgical Department, General State Hospital of Athens, Athens, Greece. \\ 3. ICU Department, King Saud Medical City, Riyadh, KSA. \\ 4. Medical Intern, Collage Of Medicine, Imam Mohammed Bin Saud University, Riyadh, KS. \\ 5. Medical student, Collage Of Medicine, Imam Mohammed Bin Saud University, Riyadh, KSA.
}

\section{Manuscript Info}

Manuscript History

Received: 29 November 2016

Final Accepted: 27 December 2016

Published: January 2017

Key words:-

Doppler ultrasound, MDCTA, MRI, flap implant.

\section{Abstract}

Introduction: The definition of a deep inferior epigastric perforator (DIEP) flap is breast reconstruction for a female who had previous surgical procedure due to any certain illness. It's usually an autologous breast reconstruction flap to minimize the scar of the breast at the site of operation.

Method: We used these significant techniques to evaluate the flap, making sure sufficient blood flow is achieved and assessing the flap's binding capacity. It must be successfully done with radiological Multidetector Doppler ultra sound and CT Angiography (MDCTA). All of them used to evaluate and demarcate the flap tissue to diminish flap rejection. Our goal was to aesthetically normalize the anomaly, correct the patient's own self image and how she perceives it.

Conclusion:

The predictability and efficiency of DIEP flap in breast reconstruction is high. Multidetector Doppler ultra sound and CT Angiography (MDCTA) are a great asset especially in the rather expansive technology-driven, and they are perfectly attributed to integrated imaging technologies, as well as they have particular advantage which reduce operative time and stress.

Copy Right, IJAR, 2016,. All rights reserved.

\section{Background:-}

The deep inferior epigastric perforator (DIEP) flap has become the gold standard for autologous breast reconstruction owing to the reduced donor site morbidity and inconspicuous scar, abundance and reliability of transferred tissue as well as texture and contour emulation to the female breast. ${ }^{1,2}$ The vascular anatomy of the DIEP and its perforators greatly varies not only among patients but also from one hemi-abdomen to the other in the same individual. Because of numerous congenital and acquired anatomical variations of the DIEP branching pattern, thorough knowledge of the perforators topography and perforator dominance is essential for accurate preoperative planning. ${ }^{3-8}$

The evolution of imaging technology has significantly contributed to the enhancement of predictability and reproducibility of DIEP breast reconstruction outcomes. Meticulous pre-operative imaging of the perforator flap and 
mapping of the vessels facilitates precise flap design and harvest, reduces operative time and intraoperative complications while it improves outcomes and efficiency. ${ }^{4,9-11}$

The selected dominant perforator is usually medially located, bares a short intramuscular course and a diameter $>1$ $\mathrm{mm}$, with an extended vascular distribution within the flap adipose tissue to match the flap and to allow preservation of muscle innervation. ${ }^{2,12}$

The pre-operative vascular mapping includes imaging modalities ranging from Color Doppler ${ }^{13}$ to sophisticated stereotactic vascular representation systems. ${ }^{11,14}$ The ideal imaging technique should have no risk to the patient, attain exceptional quality and highly informative images, and be fast and comfortable to the patient. ${ }^{11,12}$ Prerequirement for the reliability of each of the imaging techniques is a standardized protocol for accurate identification of DIEA perforators. ${ }^{13}$

This review presents current imaging methods integrated in DIEP mapping for breast reconstruction, emphasizing on ultrasonography and computed tomographic angiography.

Doppler ultrasonography:-

Doppler flowmetry for planning the DIEP flap was first described by Blondeel et al in 1998 and can access the flow velocity, patency, location, and caliber of the perforator arteries and venus tributaries. ${ }^{15}$

Color Doppler Ultrasonography (CDU) exhibits $96 \%$ sensitivity nearly $100 \%$ positive predictive value. ${ }^{16,17}$ It can identify perforators $>0.5 \mathrm{~mm}$ in diameter and can be used in pre-operative planning, intraoperative decisionmaking, and post-operative follow-up. ${ }^{16-18}$

CDU is performed the day before or the morning before the operation with the patient in supine position, as in surgery, and allows for direct visualization of the perforator as it emerges from the deep fascia of the rectus abdominis.

Following the course of the DIEA from its origin to the umbilicus, CDU scans the entire flap at a radius of approximately $10 \mathrm{~cm}$ above and laterally to the umbilicus. The penetration point of the superficial fascia of the rectus abdominis to the flap skin is exactly located and marked accurately on the skin.

CDU is a low-cost, non -ionizing, bedside examination. Although a reliable method in estimating the vessel caliber, specificity and sensitivity of CDU may vary. Expertise is required while there is interobserver variability. ${ }^{11,12}$ Subcutaneous vessels that are not perforators may be visualized resulting in false positives, while in overweight patients sensitivity further decreases. Moreover, the duration of the examination is 45-60 minutes, rendering the technique uncomfortable for the patient, who has to remain in the same position during the procedure. ${ }^{11,12}$

It is noteworthy that CDU does not provide information on the anatomic relationship between the deep inferior epigastric system and other structures, such as the superior inferior epigastric (SIE) system. In addition, as CDU is a real-time technique, further post examination analysis of data is not possible. ${ }^{11}$

\section{CT angiography (CTA):-}

The introduction of CTA in preoperative vascular mapping has significantly improved DIEP flap dissection and survival, as it provides highly accurate information concerning the arterial as well as the venous anatomy of the DIEP flap and can display DIEA's course, branching patterns, number, size, intramuscular trajectory and location of perforators. ${ }^{19-23}$ CTA has a sensitivity of $96 \%$, a positive predictive value of $95 \%$ and may identify perforators as small as $0.3 \mathrm{~mm}$. Moreover, CTA may reveal the structure and competence of the abdominal wall fascial layers. $11,12,23$

The rate and timing of the injection and the patient's cardiac output and body habitus determine the degree of enhancement. Careful optimization of single phase CTA prevents low opacification due to early scan as well as venous contamination due to late arterial phase. In multiphase CTA examination on the other hand, each phase should be independently validated and the radiation dose is multiple compared to single phase CTA. ${ }^{24}$,

Kim et al. ${ }^{25}$ reported the use of CTA to evaluate flap and recipient vessels, scanning the area from the clavicle to the pubic symphysis. They assessed the intercostal space, the internal mammary artery and vein, and the internal 
mammary artery perforator to determine which intercostal space was most appropriate. The authors also used CTA for volumetric estimation of the contralateral breast and the abdominal flap.

The use of multidetector CT increases accuracy and may provide further data on the number of perforators, their distribution and axiality to the flap subcutaneous tissue. ${ }^{12,16,17}$ This information is highly beneficial in patients with lower abdominal scars, as it facilitates selection of the best perfused region of abdominal tissue supplied by the dominant perforator. ${ }^{12,26,27}$

CTA is a three-dimensional, non-invasive, operator- independent method, highly reproducible, requiring a short scanning time of 5 minutes ${ }^{11,12}$. Apart from the high spatial resolution, ${ }^{28-30}$ there is availability of free software for post processing 3D digital reconstruction for detailed mapping of the vascular anatomy. ${ }^{11,31}$ Also 4D reconstruction adds temporal resolution enabling dynamic analysis of perforator anatomy and may be used to delineate the perforasomes in lower abdomen. ${ }^{6,11,17,32}$

Among drawbacks, is the high cost of the investigation, which may be counterbalanced by the reduction in operative time and intraoperative complications, resulting from thorough and accurate preoperative mapping. ${ }^{11,12,32}$ Another limitation is the exposure of the patient to ionizing radiation and the use of intravenous contrast medium, that is nephrotoxic and allergenic.

Compared to CDU, both methods provide reliable information about the size, localization, and course of DIE perforators. CTA is a more accurate method in detecting the course and location of perforators compared to CDU ${ }_{11,16}$ but CDU is superior to a standalone CTA examination for measuring perforator diameters. ${ }^{33-35}$ and for hemodynamic evaluation of both arterial and venous conduits of the perforator-complex. ${ }^{36}$

In order to increase the accuracy of preoperative mapping, CDU may be used in addition to CTA.
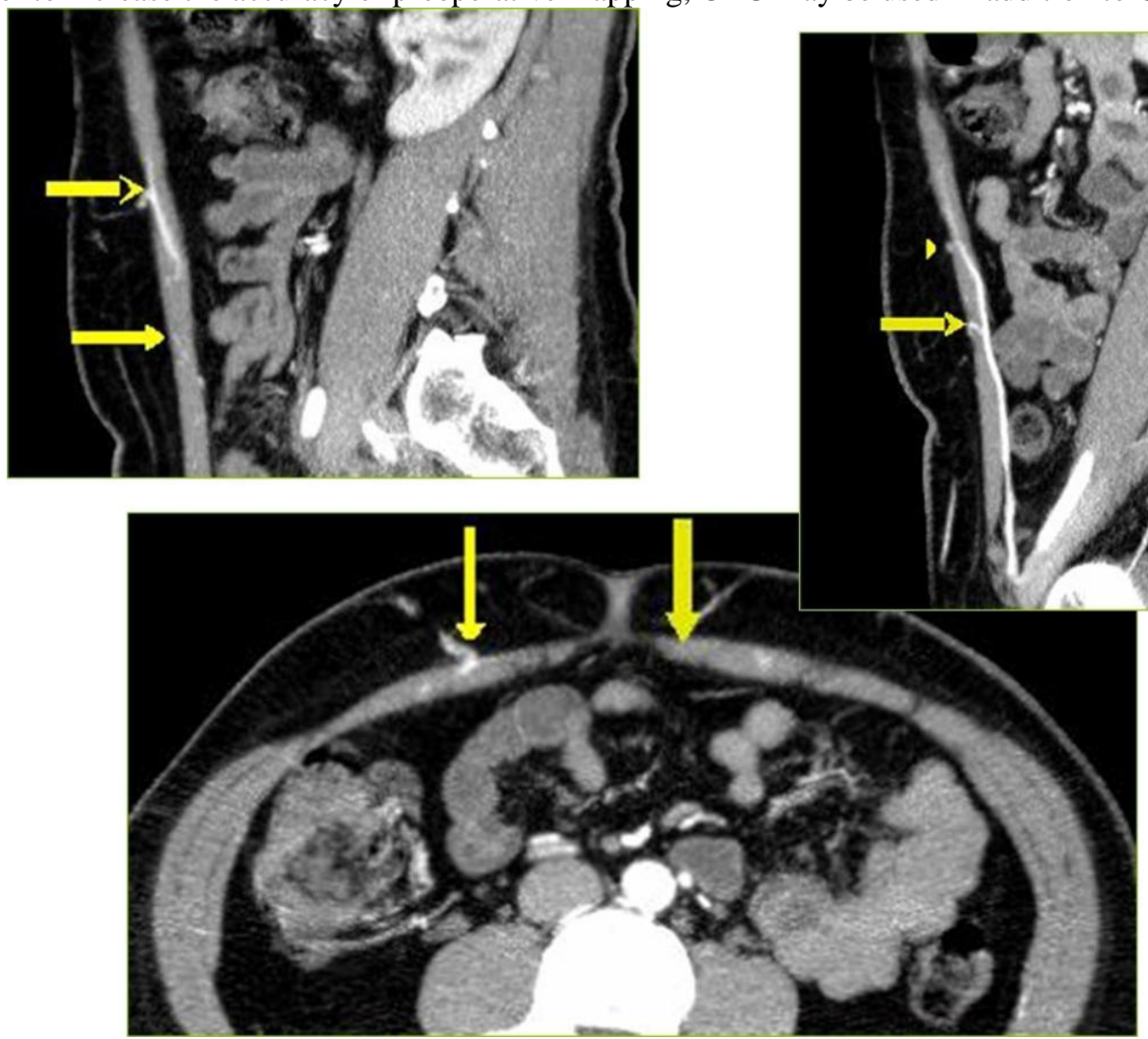

In this CTA showing the inferior epigastric artery which showing the perforator to determine for seorgone the mark line for the patient before the operation 14 . 

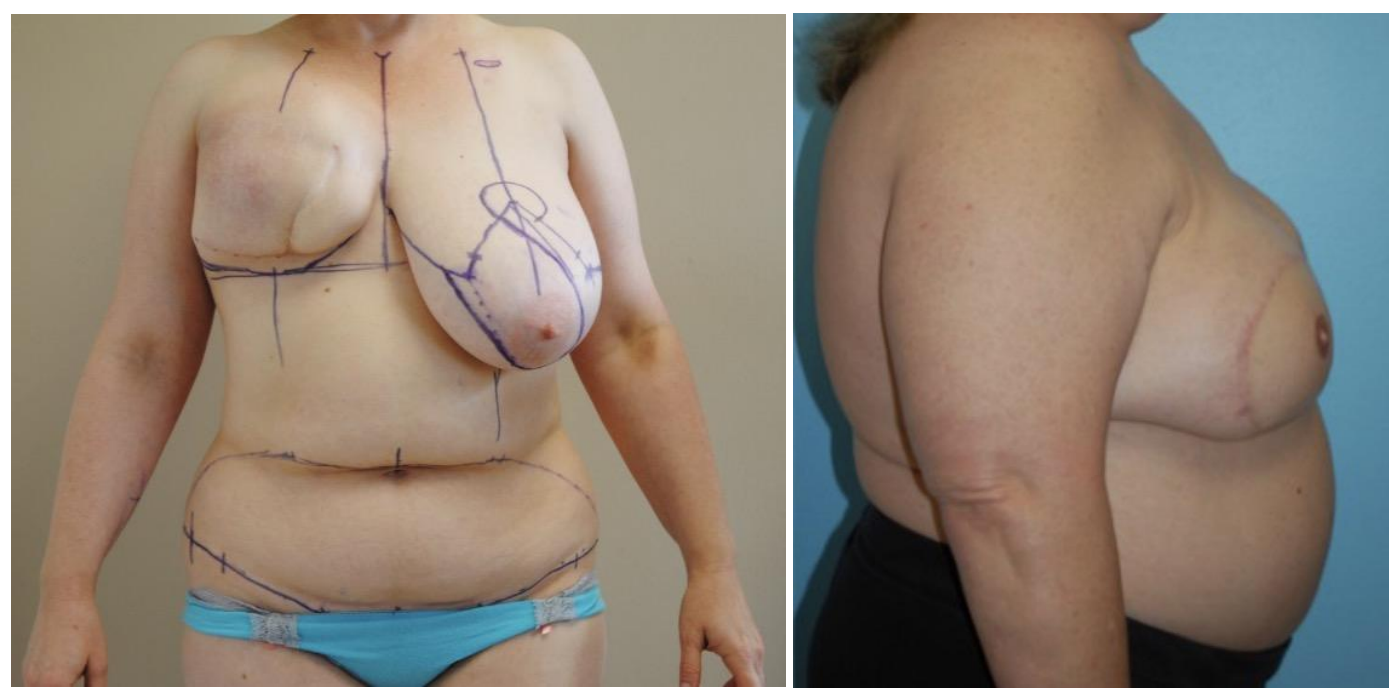

For this patient pre-operative once we compare for the left pic. Showing the scar and deformity of the breast. All this depend on the reconstruction of the breast and the prognosis.

\section{Perforator artery or perforator complex?}

Despite the fact that the majority of DIEP flaps are compromised due to venous congestion and rarely arterial insufficiency, ${ }^{37}$ all techniques were until recently spotlighting on the dominant arterial-perforator, downsizing the importance of the accompanying venous - tributaries. ${ }^{36,38}$

It is well-perceived that, although any medially located arterial perforator $>1 \mathrm{~mm}$ in diameter can perfuse any flap, not every associated vein can drain every flap. ${ }^{36}$ Lately the concept of the perforator complex, which includes the triad of an arterial perforator, venous tributaries and nerve in any combination, has been brought in, suggesting that selection of the dominant perforator-complex based on dominant veins ensures optimal flap microcirculation, while diminishing intraoperative incidents and postoperative healing complications.

Figus et al. ${ }^{38}$ demonstrated that if a dominant vein is identified first, the probability of detecting a suitable perforator- complex increases to $93.5 \%$, while significantly decreases to $69.8 \%$ when a dominant artery is identified first. ${ }^{38}$

Our team introduced the perforator- complex imaging protocol termed as "CTA-guided CDU examination", ${ }^{36}$ which combines the use of CTA and CDU in the decision-making process of choosing the best suitable perforatorcomplex. The CTA results are used as a guide to conduct a CDU examination to investigate the size and patency of the accompanying venous tributaries. Selection of the suitable perforator complex based on the size and patency of the dominant vein resulted in better flap revascularization $(\mathrm{p}<0.05)$ and decreased postoperative complications $(\mathrm{p}<0.05)$ compared to dominant artery based selected complexes. Our preliminary results indicated that this protocol may identify more optimal perforator-complexes based on venous mapping and thus, further improve the preoperative microsurgical planning. ${ }^{36}$ 


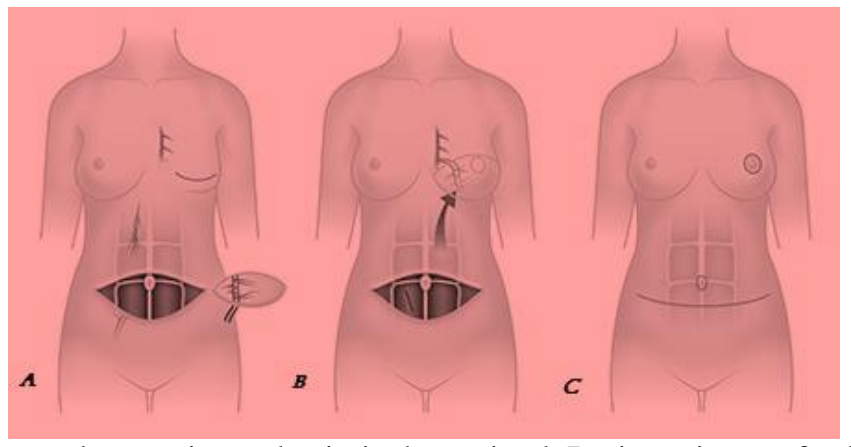

This figure. A. showing the vascular arteries and vein is determined, B. tissue is transfer from right side and anastomosed to the left breast. C. healing is done after the reconstruction and the both breast are similar. ${ }^{24}$

\section{Magnetic Resonance Angiography:-}

There is little evidence associating preoperative Magnetic resonance angiography (MRA) with improved clinical outcomes. ${ }^{39-42}$ Contrast enhanced MRA delineates accurately the intramuscular trajectory of the perforators and can identify vessels $>0.8 \mathrm{~mm}$ in diameter. ${ }^{11,40-42}$

Rozen et al. suggested that despite high sensitivity (100\%) MRA was inferior to preoperative CTA due to low specificity (50\%), ${ }^{43}$ while Chernyak et al. reported a 97\% concordance of MRA imaging with intraoperative findings in DIEP flap breast reconstruction. ${ }^{44}$

Despite its higher cost, MRA has certain advantages over CTA, namely elimination of exposure to ionizing radiation and safer required contrast medium. Nevertheless, gadolinium may also be nephrotoxic for patients with renal insufficiency. ${ }^{11,12,40-44}$

Masia et al. demonstrated that non-contrast magnetic resonance imaging was associated with high specificity and provided reliable information on the perforator branching within the subcutaneous abdominal tissue and the vascular connections between the superficial and the deep inferior epigastric vessels ${ }^{45}$

Nevertheless, a serious limitation of MRA is possible patient discomfort, as it requires breath-hold for 10-20 seconds to avoid motion artifacts. Distress levels may increase in claustrophobic patients, while the technique is contraindicated in severely obese and patients with metallic implants. ${ }^{11,39,45}$

\section{Other methods:-}

The use of dynamic infrared thermography (DIRT) for perforator mapping in DIEP flaps was first described in 1993. ${ }^{46}$ DIRT has been used in the preoperative planning, intraoperative and postoperative monitoring of flap perfusion. Thermal images are captured with an infrared camera before, during and after exposure to a cold challenge provided by a fan blowing air for 2 min over the abdomen. After a recovery period of 3 min, the first appearing hot spots correlate with reliable perforator location. ${ }^{17,47}$ Although a simple, low cost and patient safe method it can obviously provide only 2D perforator mapping, while there is no evidence supporting its accuracy

Laser-assisted indocyanine green fluorescence angiography (LA-ICGFA) ${ }^{48}$ involves peripheral injection of indocyanine green and capture of the cutaneous vascularity with the use of infrared energy. Images are recorded and software analysis data on flap perfusion and patency of anastomosis are collected. Apparently, the method, of anyway limited use, may be useful for intraoperative assessment and less for preoperative and postoperative monitoring. ${ }^{17}$

\section{Conclusions:-}

Recent improvements in the predictability and efficiency of DIEP flap in breast reconstruction are to a great extend technology-driven and attributed to integrated imaging technologies. Advances in accurate preoperative perforator imaging have resulted in significantly reduced operative time and stress, increased flap survival and consequently patient satisfaction. 
The choice of imaging technique depends on patient history, equipment availability and radiologic expertise. Standardization of protocols may further increase precision in vascular anatomy imaging and patient comfort and safety.

\section{References:-}

1. Granzow JW, Levine JL, Chiu ES, Allen RJ. Breast reconstruction using perforator flaps. J Surg Oncol 2006;94(6):441-54

2. Allen RJ, Treece P. Deep inferior epigastric perforator flap for breast reconstruction. Ann Plast Surg 1994;32(1):32-8.

3. Moon HK, Taylor GI. The vascular anatomy of rectus abdominis musculocutaneous flaps based on the deep superior epigastric system. Plast Reconstr Surg 1988;82(5):815-32.

4. Casey 3rd WJ, Chew RT, Rebecca AM, Smith AA, Collins JM, Pockaj BA. Advantages of preoperative computed tomography in deep inferior epigastric artery perforator flap breast reconstruction. Plast Reconstr Surg 2009;123(4):1148-55.

5. Ghattaura A, Henton J, Jallali N, Rajapakse Y, Savidge C, Allen S, et al. One hundred cases of abdominalbased free flaps in breast reconstruction. The impact of preoperative computed tomographic angiography. J Plast Reconstr Aesthet Surg 2010;63(10):1597-601.

6. Wong C, Saint-Cyr M, Mojallal A, Schaub T, Bailey SH, Myers S,et al. Perforasomes of the DIEP flap: vascular anatomy of the lateral versus medial row perforators and clinical implications. Plast Reconstr Surg 2010;125(3):772-82.

7. Canizares O, Mayo J, Soto E, Allen RJ, Sadeghi A. Optimizing Efficiency in Deep Inferior Epigastric Perforator Flap Breast Reconstruction. Ann Plast Surg 2015 Aug;75(2):186-92.

8. Rozen WM, Palmer KP, Suami H, Pan WR, Ashton MW, Corlett RJ, et al. The DIEA branching pattern and its relationship to perforators: the importance of preoperative computed tomographic angiography $\mathrm{f}$ or DIEA perforator fla ps. Plast Reconstr Surg .2008;121(2):367-73.

9. Keys KA, Louie O, Said HK, Neligan PC, Mathes DW. Clinical utility of CT angiography in DIEP breast reconstruction. J Plast Reconstr Aesthet Surg 2013 Mar;66(3):e61-5

10. Malhotra A(1), Chhaya N, Nsiah-Sarbeng P, Mosahebi A. CT-guided deep inferior epigastric perforator (DIEP) flap localization -- better for the patient, the surgeon, and the hospital. Clin Radiol 2013 Feb;68(2):131-8.

11. Aubry S, Pauchot J, Kastler A, Laurent O, Tropet Y, Runge M. Preoperative imaging in the planning of deep inferior epigastric artery perforator flap surgery. Skeletal Radiol 2013 Mar;42(3):319-27

12. Masia J, Clavero JA, Larranaga JR, Alomar X, Pons G, Serret P. Multidetector-row computed tomography in the planning of abdominal perforator flaps. J Plast Reconstr Aesthet Surg 2006;59(6):594-9.

13. Giunta RE, Geisweid A, Feller AM. The value of preoperative Doppler sonography for planning free perforator flaps. Plast Reconstr Surg 2000;105(7):2381-6.

14. Rozen WM, Ashton MW, Stella DL, Phillips TJ, Taylor GI. Stereotactic image-guided navigation in the preoperative imaging of perforators for DIEP flap breast reconstruction. Microsurgery 2008;28(6):417-23

15. Blondeel PN, Beyens G, Verhaeghe R, Van Landuyt K, Tonnard P, Monstrey SJ, et al. Doppler flowmetry in the planning of perforator flaps. Br J Plast Surg 1998;51(3):202-9.

16. Cina A, Salgarello M, Barone-Adesi L, Rinaldi P, Bonomo L. Planning breast reconstruction with deep inferior epigastric artery perforating vessels: multidetector CT angiography versus color Doppler US. Radiology. 2010;255(3):979-87.

17. Mohan AT. Saint-Cyr M. Advances in imaging technologies for planning breast Reconstruction. Gland Surg 2016;5(2):242-254

18. Heitland AS, Markowicz M, Koellensperger E, Schoth F, Feller AM, Pallua N. Duplex ultrasound imaging in free transverse rectus abdominis muscle, deep inferior epigastric artery perforator, and superior gluteal artery perforator flaps: early and long-term comparison of perfusion changes in free flaps following breast reconstruction. Ann Plast Surg 2005 Aug;55(2):117-21

19. Rozen WM, Anavekar NS, Ashton MW, Stella DL, Grinsell D, Bloom RJ, et al. Does the preoperative imaging of perforators with CT angiography improve operative outcomes in breast reconstruction? Microsurgery 2008;28(7):516-23.

20. Phillips TJ, Stell a DL, R ozen WM, Ashton M, Taylor GI. Abdominal wall CT angiography: a detailed account of a newly established preoperative imaging technique. Radiology 2008;249(1):32-44.

21. Alonso-Burgos A, Garcia-Tutor E, Bastarrika G, Cano D,Martinez-Cuesta A, Pina LJ. Preoperative planning of deep inferior epigastric artery perforator flap reconstruction with multislice-CT angiography: imaging findings and initial experience. J Plast Reconstr Aesthet Surg 2006;59(6):585-93. 
22. Rozen WM, Ashton MW, Stella DL, Phillips TJ, Taylor GI. The accuracy of computed tomographic angiography for mapping the perforators of the DIEA: a cadaveric study. Plast Reconstr Surg 2008;122(2):3639.

23. Rozen WM, Chubb D, Ashton MW, Webster HR. Mapping the vascular anatomy of free transplanted soft tissue flaps with computed tomographic angiography. Surg Radiol Anat 2011.

24. Pellegrin A, Stocca T, Belgrano M, Bertolotto M, Pozzi-Mucelli F, Marij Arnež Z, Cova MA. Preoperative vascular mapping with multislice $\mathrm{CT}$ of deep inferior epigastric artery perforators in planning breast reconstruction after mastectomy. Radiol Med 2013 Aug;118(5):732-43.

25. Kim H, Lim SY, Pyon JK, Bang SI, Oh KS, Mun GH. Preoperative computed tomographic angiography of both donor and recipient sites for microsurgical breast reconstruction. Plast Reconstr Surg. 2012 Jul;130(1):11e-20e

26. De Frene B, Van Landuyt K, Hamdi M, Blondeel P, Roche N, Voet D, Monstrey S .Free DIEAP and SGAP flap breast reconstruction after abdominal/gluteal liposuction. J Plast Reconstr Aesthet Surg 2006;59(10):1031-6.

27. Hamdi M, Larsen M, Craggs B, Vanmierlo B, Zeltzer A. Harvesting free abdominal perforator flaps in the presence of previous upper abdominal scars. J Plast Reconstr Aesthet Surg 2014 Feb;67(2):219-2

28. Teoh R, Johnson RF, Nishino TK, Ethridge RT. Evaluation of three-dimensional computed tomography processing for deep inferior epigastric perforator flap breast reconstruction. Can J Plast Surg 2007;15(4):196-8.

29. Laungani AT, Van Alphen N, Christner JA, Lachman N, Pawlina W, Ballman KV, Saint-Cyr M. Threedimensional CT angiography assessment of the impact of the dermis and the subdermal plexus in DIEP flap perfusion. . J Plast Reconstr Aesthet Surg 2015 Apr;68(4):525-30

30. Hummelink S, Hameeteman M, Hoogeveen Y, Slump CH, Ulrich DJ, Schultze Kool LJ. Preliminary results using a newly developed projection method to visualize vascular anatomy prior to DIEP flap breast reconstruction. J Plast Reconstr Aesthet Surg 2015 Mar;68(3):390-4.

31. Chae MP, Hunter-Smith DJ, Rozen WM. Comparative study of software techniques for 3D mapping of perforators in deep inferior epigastric artery perforator flap planning. Gland Surg 2016 Apr;5(2):99-106

32. Rozen WM, Garcia-Tutor E, Alonso-Burgos A, Acosta R, StillaertF, Zubieta JL, et al. Planning and optimising DIEP flaps with virtual surgery: the Navarra experience. J Plast Reconstr Aesthet Surg 2010;63(2):289-97.

33. Klasson S, Svensson H, Malm K), Wassélius J, Velander P. Preoperative CT angiography versus Doppler ultrasound mapping of abdominal perforator in DIEP breast reconstructions: A randomized prospective study. $\mathrm{J}$ Plast Reconstr Aesthet Surg 2015 Jun;68(6):782-6.

34. Rozen WM, Phillips TJ, Ashton MW, Stella DL, Gibson RN, Taylor GI. Preoperative imaging for DIEA perforator flaps: a comparative study of computed tomographic angiography and doppler ultrasound. Plast Reconstr Surg 2008;121(1 Suppl):1-8.

35. Vandevoort M, Vranckx JJ, Fabre G. Perforator topography of the deep inferior epigastric perforator flap in 100 cases of breast reconstruction. Plast Reconstr Surg 2002;109(6):1912-8.

36. Gravvanis A1, Tsoutsos D, Papanikolaou G, Diab A, Lambropoulou P, Karakitsos D Refining perforator selection for deep inferior epigastric perforator flap: the impact of the dominant venous perforator. Microsurgery 2014 Mar;34(3):169-76.

37. Blondeel PN, Arnstein M, Verstraete K, Depuydt K, Van Landuyt KH, Monstrey SJ, et al. Venous congestion and blood flow in free transverse rectus abdominis myocutaneous and deep inferior epigastric perforator flaps. Plast Reconstr Surg 2000;106(6):1295-9.

38. Figus A, Wade RG, Gorton L, Rubino C, Griffiths MG, Ramakrishnan VV.

39. Venous perforators in DIEAP flaps: an observational anatomical study using duplex ultrasonography. J Plast Reconstr Aesthet Surg 2012 Aug;65(8):1051-9.

40. Schaverien MV, Ludman CN, Neil-Dwyer J, Perks GB, Akhtar N, Rodrigues JN, Benetatos K, Raurell A, Rasheed T, McCulley SJ. Contrast-enhanced magnetic resonance angiography for preoperative imaging in DIEP flap breast reconstruction. Plast Reconstr Surg 2011 Jul;128(1):56-62

41. Newman TM, Vasile J, Levine JL, Greenspun DT, Allen RJ, ChaoMT, et al. Perforator flap magnetic resonance angiography for reconstructive breast surgery: a review of 25 deep inferior epigastric and gluteal perforator artery flap patients. J Magn Reson Imaging 2010;31(5):1176-84

42. Vasile JV, Levine JL. Magnetic resonance angiography in perforator flap breast reconstruction. Gland Surg 2016 Apr;5(2):197-211

43. Neil-Dwyer JG, Ludman CN, Schaverien M, McCulley SJ, Perks AG. Magnetic resonance angiography in preoperative planning ofdeep inferior epigastric artery perforator flaps. J Plast Reconstr Aesthet Surg 2009;62(12):1661-5.

44. Rozen WM, Stella DL, Bowden J, Taylor GI, Ashton MW. Advances in the pre-operative planning of deep inferior epigastric artery perforator flaps: magnetic resonance angiography. Microsurgery 2009; 
29(2):119-231 .45

46. Chernyak V, Rozenblit AM, Greenspun DT, Levine JL, MilikowDL, Chia FA, et al. Breast reconstruction with deep inferior epigastric artery perforator flap: 3.0-T gadolinium-enhanced MR imaging for preoperative localization of abdominal wall perforators. Radiology 2009;250(2):417-24.

47. Masia J, Kosuotic D, Cervelli D, Clavero JA, Monill JM, Pons G. In search of the ideal method in perforator mapping: non contrast magnetic resonance imaging. J Reconstr Microsurg 2010 Jan;26(1):29-35.

48. Itoh Y, Arai K. Use of recovery-enhanced thermography to localize cutaneous perforators. Ann Plast Surg1995;34:507-11.

49. Weum S, Mercer JB, de Weerd L. Evaluation of dynamic infrared thermography as an alternative to CT angiography for perforator mapping in breast reconstruction: a clinical study. BMC Med Imaging 2016 Jul $15 ; 16(1): 43$

50. Liu DZ, Mathes DW, Zenn MR, et al. The application of indocyanine green fluorescence angiography in plastic surgery. J Reconstr Microsurg 2011;27:355-64. 